УДК $544.478+544.032$

ТЕМПЛАТНЫЙ СИНТЕЗ ПОРИСТЫХ МОНОСИЛИКАТОВ КАЛЬЦИЯ С ИСПОЛЬЗОВАНИЕМ СИЛОКСАН-АКРИЛАТНЫХ ЭМУЛЬСИЙ

${ }^{1,2}$ Папынов Е.К., ${ }^{1}$ Майоров В.Ю., ${ }^{2}$ Модин Е.Б., ${ }^{1}$ Каплун Е.В.,

${ }^{1,2}$ Сокольницкая Т.А., ${ }^{1,2}$ Авраменко В.А.

${ }^{1}$ ФББУН «Институт химии» ДВО РАН, Владивосток, e-mail: ttt@ich.dvo.ru;

${ }^{2}$ Дальневосточный федеральный университет, Владивосток

Предложен метод темплатного золь-гель синтеза пористых моносиликатов кальция. Показана возможность получения упорядоченно пористой структуры в силикатных материалах с макроразмерными порами за счет использования силоксан-акрилатных эмульсий в качестве темплата. Определено влияние условий термического процесса при удалении органического темплата на морфологические параметры наноструктурированных силикатов. Выявлены оптимальные параметры термической обработки силикатных ксерогелей на стадии формирования макропористой структуры синтезируемых материалов. Представлен способ получения консолидированных макропористых материалов на основе волластонита с иммобилизованными наночастицами золота, основанный на использовании предварительно модифицированного темплата функционализированной силоксан-акрилатной эмульсии. Успешно синтезированы пористые керамические композиты на основе наноструктурированного волластонита, относящиеся к классу биоактивных керамических материалов, перспективных для медицинской практики.

Ключевые слова: темплатный синтез, макропористые силикаты, наночастицы золота

\title{
TEMPLATE SYNTHESIS OF POROUS CALCIUM MONOSILICATES USING SILOXANE-ACRYLATE LATEXES
}

\author{
1,2Papynov E.K., ${ }^{1}$ Mayorov V.Y., ${ }^{2}$ Modin E.B., ${ }^{1}$ Kaplun E.V., \\ 1,2Sokolnitskaya T.A., ${ }^{1,2}$ Avramenko V.A. \\ ${ }^{1}$ Institute of chemistry Far Eastern Branch of Russian Academy of Sciences, \\ Vladivostok,e-mail: ttt@ich.dvo.ru; \\ ${ }^{2}$ Far Eastern Federal University, Vladivostok
}

\begin{abstract}
Here we suggest a new method of template sol-gel synthesis of porous calcium monosilicates and show that the ordered macroporous structures can be obtained for silicate materials using siloxane-acrylate latexes as a template. Effect of thermal conditions during template destruction on morphological properties of nanostructured silicates have been elucidated. Optimal parameters of thermal treatment of silicate xerogels for formation of macroporous structure of synthesized materials were established. The method for producing of consolidated macroporous materials based on wollastonite with immobilized gold nanoparticles is presented. This method includes using of a pre-modified template - functionalized siloxane-acrylate emulsion with impregnated gold nanoparticles. Porous ceramic composites based on nanostructured wollastonite have been successfully synthesized. The materials obtained can be classified as bioactive ceramics, which are promising for medical applications.
\end{abstract}

Keywords: template synthesis, macroporous silicates, gold nanoparticles

Моносиликаты кальция привлекают внимание исследователей в течение очень длительного времени [4]. Такой интерес объясняется как чрезвычайно широким спектром применения моносиликатов в практике, так и практически неограниченными запасами природного и техногенного сырья, пригодного для их получения. Высокопористые моносиликаты кальция представляют интерес как сорбенты [5], термоизолирующие покрытия [3], биосовместимые материалы [9, 13]. Синтетические моносиликаты кальция могут быть получены множеством способов, описание большинства из которых приведено в [4], от простого смешения реагентов [5] до использования мезопористых кремнеземных структур типа SBA-15 в качестве одного из прекурсоров синтеза [11]. Однако большинство материалов получается в форме ги- дросиликатов, пористая структура которых претерпевает существенные изменения при термической обработке. В то время как для биомедицины важны прочные пористые материалы на основе наиболее устойчивой формы моносиликата кальция - волластонита. Темплатный синтез моносиликатов кальция с использованием в качестве темплат различных коллоидных частиц (мицелл, микроэмульсий, латексов, растворимых наночастиц, (например, карбоната кальция)) в последнее время привлекает внимание многих исследователей $[10,11,14]$. Успешно синтезированы полые наночастицы для переноса лекарственных препаратов [14], нанопроволока волластонита для включения в различные композиционные материалы [10]. Целью настоящей работы была разработка методов темплатного синтеза моносиликатов кальция с использованием 
дешевых промышленных темплат - силоксан-акрилатных эмульсий и попытка создания консолидированных пористых материалов на основе волластонита, содержащих наночастицы благородных металлов. Такие материалы в настоящее время востребованы медициной [13].

\section{Экспериментальная часть}

В качестве темплата использовали промышленную силоксан-акрилатную эмульсию КЭ 13-36 (содержание твердой фазы $50 \%$, средний размер частиц 160 нм) производства ООО «Астрохим» (г. Электросталь), коллоидные свойства которой описаны в [1].

Синтез эмульсии, содержащей наночастицы золота, проводили добавлением необходимого количества $\mathrm{H}\left[\mathrm{AuCl}_{4}\right]$ к раствору эмульсии в 0,05 н $\mathrm{NaOH}$ и нагреванием эмульсии при $100^{\circ} \mathrm{C}$. При этом эмульсия приобретает характерный цвет от розового (1 мг Au на 1 г сухого полимера) до серо-синего (более 2,5 мг Au на 1 г сухого полимеpa), обусловленный плазмонным поглощением наночастиц золота [8].
Синтез макропористого материала осуществляли по следующей схеме. К раствору эмульсии с разбавлением 1:10 добавляли 1,0 н раствор хлорида кальция и 1,0 н раствор метасиликата кальция. После перемешивания смесь отфильтровывали, промывали до отрицательной реакции на хлорид ионы и сушили. Полученный материал для удаления органического темплата отжигали в атмосфере воздуха при температуре $550^{\circ} \mathrm{C}$.

Удельную поверхность полученных материалов определяли на приборе ASAP2020 (Micromeritics, США). Распределение пор по размерам определяли на ртутном поpoмере AutoPore IV (Micromeritics, США). Идентификацию фаз осуществляли с помощью рентгенофазового анализа (РФА) на дифрактометре Дрон-3 (Россия). Изображения СЭМ получены на электронном микроскопе S-3400N (Hitachi, Япония).

Общая схема синтеза силикатных материалов на основе силоксан-акрилатных эмульсий и моносиликатов кальция показана на рис. 1.

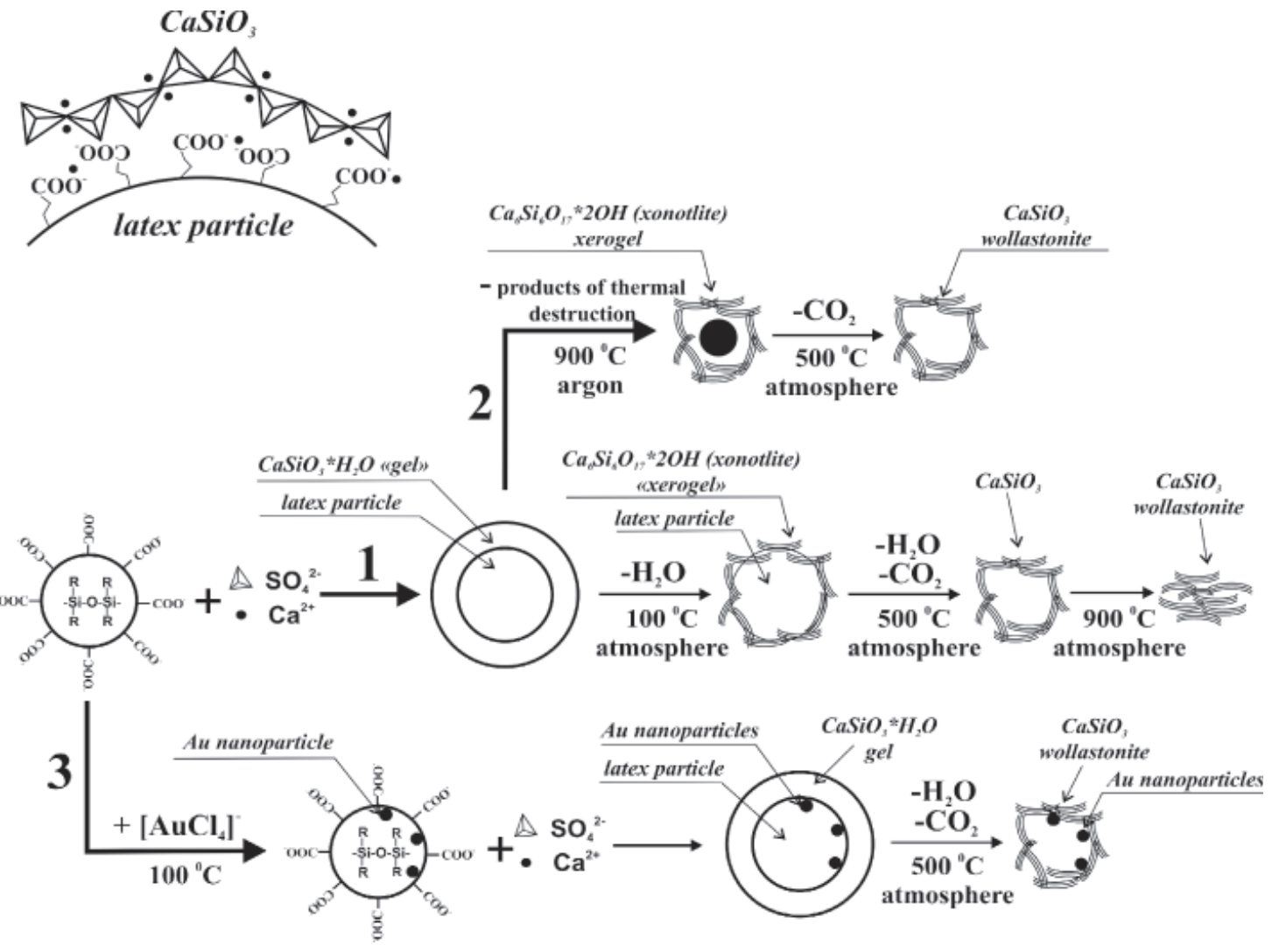

Рис. 1. Схема синтеза силикатных материалов на основе силоксан-акрилатных эмульсий. Возможны три пути синтеза:

1 - прямой синтез силиката кальция (волластонита); 2 - синтез волластонита с упорядоченной макропористой структурой; 3 - синтез макропористого волластонита с иммобилизованными наночастицами золота 


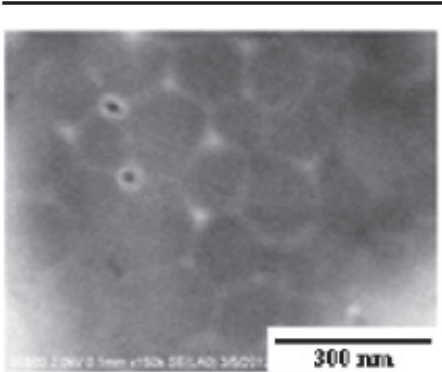

a

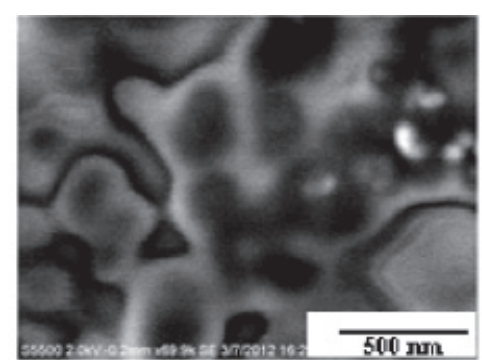

6

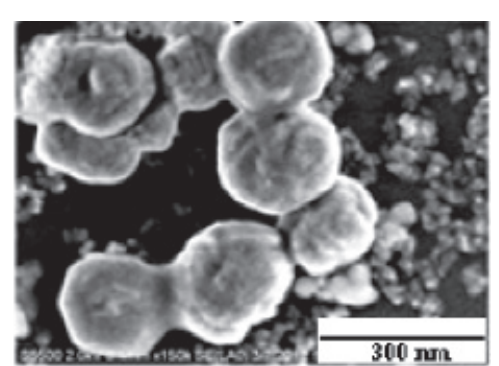

B

Рис. 2. СЭМ-изображения пленок дисперсии силоксан-акрилатной эмульсии с гидросиликатом кальция при различных молярных соотношениях емкости эмульсии к молярному содержанию силиката кальция: $a-1: 1 ; 6-1: 2 ; 8-1: 4$

Возможный механизм образования силикатной оболочки вокруг частиц силоксан-акрилатной эмульсии иллюстрируют СЭМ-изображения пленок с различным соотношением молярной емкости ионогенных групп эмульсии к молярной концентрации силиката кальция в исходной дисперсии. Такие пленки были получены поочередным введением порций нитрата кальция и силиката натрия, пропорциональных молярной емкости эмульсии (рис. 2).

Из рисунка видно, что при больших отношениях емкости эмульсии к молярному содержанию силиката кальция в системечастицы силиката кальция локализуются в областях связности частиц эмульсии, и, при дальнейшем увеличении содержания силиката кальция, образуется сплошная силикатная оболочка вокруг частиц эмульсии. При этом коллоидная система становится неустойчивой и происходит разделение фаз - твердой, содержащей композитный (включающий частицы силоксан-акрилатной эмульсии) силикат кальция, и жидкой, содержащей неорганические соли.

Такое образование силикатной оболочки вокруг частиц силоксан-акрилатной эмульсии позволяет предотвращать слияние частиц эмульсии в процессе восстановительного синтеза наночастиц благородных металлов в системе нанореактор (частица эмульсии) - раствор - гель неорганического прекурсора и, соответственно, контролировать рост наночастиц в системе. Примеры такого синтеза материалов, содержащих наночастицы благородных металлов, будут приведены ниже.

Отделение жидкой фазы легко осуществляется фильтрацией. Промывка твердой фазы дистиллятом не приводит к вымыванию эмульсии. Сушка твердой фазы при $100^{\circ} \mathrm{C}$ дает прочный композитный материал, состоящий из силоксан-акрилатной эмульсии, распределенной в объеме гидро- силиката кальция. При повышении температуры прокаливания происходит потеря несвязанной воды с образованием ксонотлита $\mathrm{Ca}_{6}\left[(\mathrm{OH})_{2} \mathrm{Si}_{6} \mathrm{O}_{17}\right]$. Дальнейшее прокаливание приводит к выгоранию органической части композитного материала и образованию макропористого силиката кальция. При этом состав твердой фазы зависит от температуры прокаливания. Рентгенофазовый анализ образцов показывает переход от низкоорганизованной, практически рентгеноаморфной фазы при температуре прокаливания $600^{\circ} \mathrm{C}$, к фазе волластонита при прокаливании при $900^{\circ} \mathrm{C}$ и выше.

В таблице приведены значения удельной поверхности материала при разных температурах прокаливания. Видно, что до температуры кальцинации $\left(600^{\circ} \mathrm{C}\right)$ удельная поверхность и объем пор материала остаются практически неизменными, но начиная с $700^{\circ} \mathrm{C}$ удельная поверхность и объем пор начинают уменьшаться с образованием при $900^{\circ} \mathrm{C}$ практически непористого материала.

Получение высокопористого волластонита, перспективного как составная часть так называемых биостекол [9], возможно с использованием следующей схемы (рис. 1 синтез 2). Прокаливание композита силикат кальция - силоксан-акрилатная эмульсия проводят в инертной атмосфере при $900^{\circ} \mathrm{C}$. Образовавшиеся карбонизованные частицы эмульсии не позволяют образоваться сплошной массе волластонита. После такого прокаливания температура композита понижается до $600^{\circ} \mathrm{C}$, и прокалка ведется в атмосфере воздуха. При этом карбонизованные частицы эмульсии сгорают, формируя макропоры. При этом фазовая структура волластонита сохраняется, о чем свидетельствуют данные РФА.

СЭМ-изображение полученного материала приведено на рис. 3 , а. Распределение пор по размеру по результатам ртутной порометрии показано на рис. 3 , б. 
Удельная поверхность силикатов кальция, полученных при различных температурах прокаливания

\begin{tabular}{|l|c|}
\hline \multicolumn{1}{|c|}{ Образец } & Удельная поверхность, $\mathrm{M}^{2} / \Gamma$ \\
\hline Синте3 1 по схеме рис. $1, T_{\text {прок }}=400^{\circ} \mathrm{C}$ & 84,9 \\
\hline Синте3 1 по схеме рис. $1, T_{\text {прок }}=500^{\circ} \mathrm{C}$ & 103,4 \\
\hline Синте3 1 по схеме рис. $1, T_{\text {прок }}=600^{\circ} \mathrm{C}$ & 105,1 \\
\hline Синте3 1 по схеме рис. $1, T_{\text {прок }}=700^{\circ} \mathrm{C}$ & 54,5 \\
\hline Синте3 1 по схеме рис. $1, T_{\text {прок }}=800^{\circ} \mathrm{C}$ & 4,3 \\
\hline Синте3 1 по схеме рис. $1, T_{\text {прок }}=900^{\circ} \mathrm{C}$ & 0,15 \\
\hline Синте3 2 по схеме рис. $1, T_{\text {прок }}=900^{\circ} \mathrm{C} \mathrm{(аргон)}+500^{\circ} \mathrm{C}$ (воздух) & 47,1 \\
\hline
\end{tabular}

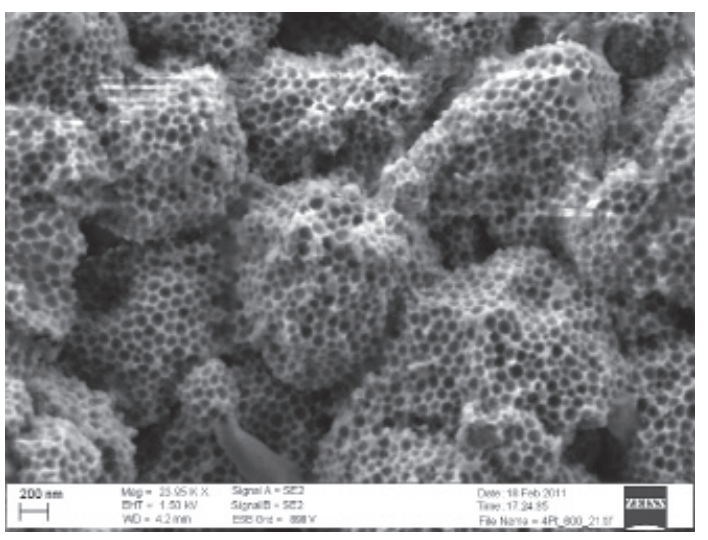

a

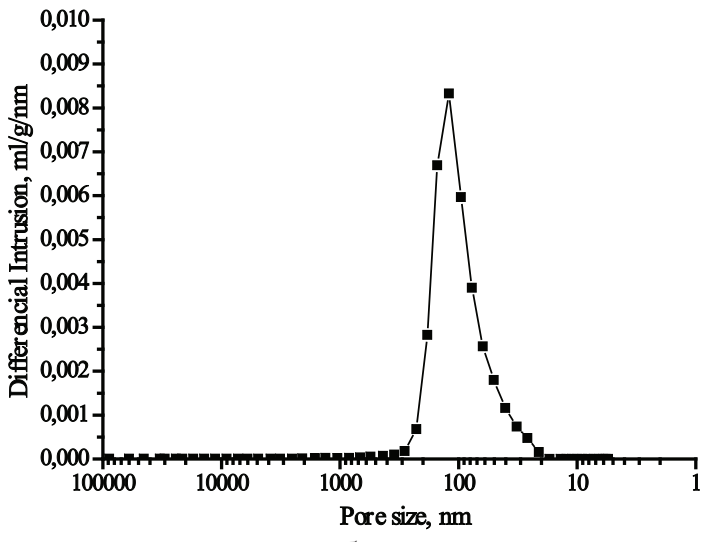

6

Рис. 3. Результаты исследований макропористого волластонита: $a-C Э M ; \sigma-$ порометрия

Другие золь-гель методы получения силиката кальция, например описанные в [12], не приводят к получению пористых структур с кристаллической фазой волластонита, а следовательно, будут обладать меньшей прочностью и большим выщелачиванием в биологических средах. Альтернативным способом получения пористого волластонита является метод самораспространяющегося высокотемпературного синтеза [6], однако получение узкого или иерархического распределения пор в таком процессе невозможно, что и видно из результатов, представленных в работе.

Еще одним важным результатом, полученным в данной работе, являются силикатные материалы, содержащие наночастицы золота. Получение пористых материалов, содержащих наночастицы благородных металлов в пористой структуре, достижимо многочисленными способами. Одним из наиболее перспективных способов является темплатный синтез пористого материала на темплатах, содержащих иммобилизованные наночастицы благородных металлов [2]. В настоящей работе синтез наночастиц зо- лота осуществляли термическим восстановлением хлораурата золота в растворе силоксан-акрилатной эмульсии, как описано в [2]. Схема получения пористого волластонита с наночастицами золота представлена на рис. 1 (синтез 3).

Для эмульсий типа гидрофобное ядро гидрофильная оболочка восстановление золота происходит за счет декарбоксилирования полиакрилатной составляющей блоксилоксан-акрилатного сополимера. На приведенных ПЭМ-изображениях (рис. 4, а) видно, что частицы эмульсии, содержащие золотые наночастицы, в отличие от исходных эмульсий имеют более широкое распределение по размерам.

Причем с увеличением количества хлораурата, вводимого в эмульсию для получения наноразмерного золота, увеличивается ширина распределения частиц золота по размерам. При этом изменяется цвет эмульсии от розового до серо-синего, что связано с изменением максимума поглощения пика плазмонного резонанса с увеличением размеров золотых металлических частиц. Одним из возможных механизмов такого 
укрупнения является уменьшение коллоидной устойчивости частиц эмульсии с восстановленными наночастицами золота за счет снижения числа карбоксильных групп в гидрофильной оболочке.

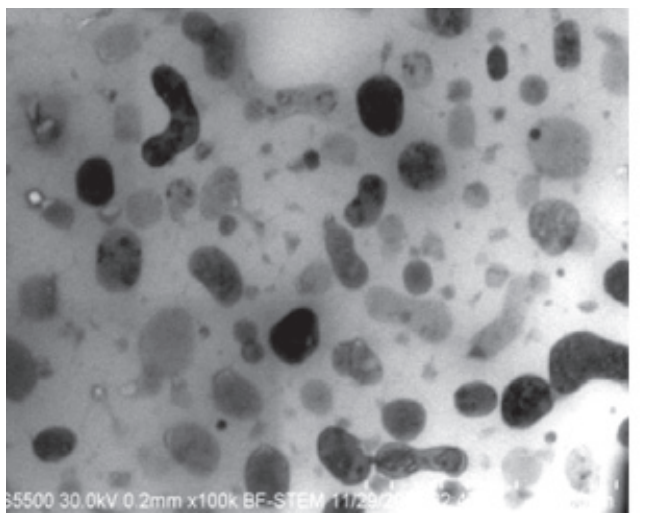

a тах. Использование темплат с различным размером частиц в такой схеме синтеза позволит получать пористые материалы с иерархической структурой пор - особо перспективные материалы для биокерамики.

Рис. 4. Результаты электронной микроскопии при исследовании наночастии золота в образиах: a-в латексах (ПЭМ-изображение); б - в пористом волластоните (СЭМ-изображение)

Восстановление золота карбоксильными группами частиц эмульсии, уже включенных в структуру силиката кальция, позволяет существенно увеличить концентрацию золотых частиц, иммобилизованных в эмульсии, без увеличения их размера. Так, увеличение содержания золота в системе силоксан-акрилатная эмульсия - силикат кальция до 50 мг на грамм сухой эмульсии не приводит к укрупнению частиц металлического золота, о чем можно судить по сохраняющейся розово-красной окраске системы. Последующая обработка материала сушка и кальцинация при $500^{\circ} \mathrm{C}$ - приводит к получению пористого материала, содержащего до 10 весовых процентов наноразмерного золота, равномерно распределенного в пористой системе. СЭМизображение такого материала приведено на рис. 4, б.

\section{Заключение}

Методом темплатного золь-гель синтеза получены высокопористые моносиликаты кальция (волластониты). Показана возможность получения упорядоченно пористой структуры в силикатных материалах за счет использования силоксанакрилатных эмульсий в качестве темплата и определенных режимов температурной обработки. Представленный в данной работе материал может быть перспективен для биотехнологии как составная часть пористых биостекол в костных имплан-

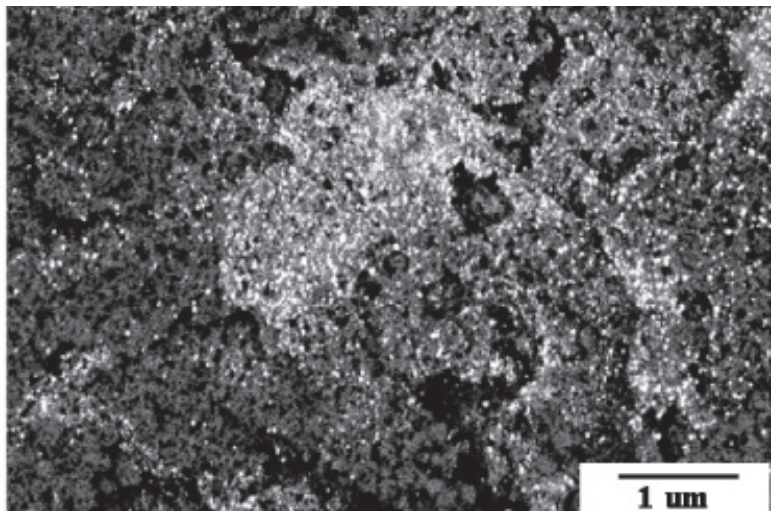

6
Использование предварительно модифицированного темплата - силоксанакрилатной эмульсии с введенным в неё хлорауратом, с последующим восстановлением, позволяет получить пористый материал, содержащий до 10 весовых процентов наноразмерного золота, равномерно распределенного в пористой системе. Такие материалы могут найти широкое применение в биомедицине как составляющие биостекол для имплантов [13].

Работа выполнена при поддержке комплексной программы фундаментальных исследований ДВО РАН «Дальний Восток» проект № 0265-2015-0024 u, частично, в рамках работ по теме госзадания № 0265-2014-0001.

\section{Список литературы}

1. Авраменко В.А., Братская С.Ю., Егорин А.М., Марковцева Т.Г., Рябушкин А.Н., Harjula R. Наноразмерные латексы, содержащие полиакриловую кислоту, и их роль в переносе и фиксации радионуклидов на объектах атомной энергетики // Вопросы радиационной безопасности. 2008. - № 4. - С. 23-29

2. Авраменко В.А., Братская С.Ю., Папынов Е.К., Майоров В.Ю., Паламарчук М.С. Макропористые катализаторы для жидкофазного окисления на основе оксидов марганца и вольфрама // Вестн. ДВО РАН. - 2011. - № 5. - С. 76-87.

3. Балкевич В.Л. Техническая керамика. - М.: Стройиздат, 1984. - $256 \mathrm{c}$.

4. Гладун В.Д., Акатьева Л.В., Холькин А.И. Синтетические силикаты кальция. - М.: Ирисбук, 2011. - 232 с.

5. Гладун В.Д., Андреева Н.Н., Акатьева Л.В., Драгина О.В. Неорганические сорбенты из техногенных отходов для очистки сточных вод промышленных 
предприятий // Экология и промышленность России. 2000. - № 5. - C. 17-20.

6. Chakradhar R.P. S., Nagabhushana B.M., Chandrappa G.T., Ramesh K.P., Rao J.L. Solution combustion derived nanocrystalline macroporous wollastonite ceramics // Materials Chemistry and Physics. - 2006. - Vol. 95, № 1. P. 169-175.

7. Hoa L.M.K., Lu M., Zhang Y. Preparation of porous materials with ordered hole structure // Adv. Colloid and Interface Sci. - 2006. - Vol. 121. - P. 9-23.

8. Koetz J, Kosmella S. Polyelectrolytes and Nanoparticles. - New York: Springer, 2007

9. Kokubo T., Kim H-M., Kawashita M. Novel bioactive materials with different mechanical propertis // Biomaterials. 2003. - Vol. 24. - P. 2161-2175.

10. Lin K., Chang J., Lu J. Synthesis of wollastonite nanowires via hydrothermal microemulsion methods. // Materials Letters - 2006. - Vol. 60. - P. 3007-3010.

11. Li X., Shi J., Zhu Y., Shen W., Li H., Liang J., Gao J.A Template Route to the Preparation of Mesoporous Amorphous Calcium Silicate With High In Vitro BoneForming Bioactivity. // Journal of Biomedical Materials Research Part B: Applied Biomaterials - 2007. - Vol. 83B, № 2. - P. 431-439.

12. Simitzis J., Baciu D. E. In Vitro bioactivity investigation of porous calcium silicate bioactive glasses prepared by sol-gel using PEG beads as template. // Digest Journal of Nanomaterials and Biostructures. - 2012. - Vol. 7, № 4. P. 1719-1725.

13. Simon S., Ciceo-Lucacel R., Radu T., Baia L. Gold nanoparticles developed in sol-gel derived apatite - bioactive glass composites // J. Mater. Sci.: Mater. Med. - 2012. - Vol. 23. P. $1193-1201$.

14. Lou X.W., Archer L.A., Yang Z. Hollow Micro-/Nanostructures: Synthesis and Applications // Advanced Materials. 2008. - Vol. 20. - P. 3987-4019.

\section{References}

1. Avramenko V.A., Bratskaya S.Yu., Egorin A.M., Markovtseva T.G., Ryabushkin A.N., Harjula R. Voprosy radiatsionnoy bezopasnosti, 2008, no. 4, pp. 23-29.

2. Avramenko V.A., Bratskaya S.Yu., Papynov E.K., Mayorov V.Yu., Palamarchuk M.S. Vestnik DVO RAN, 2011, no. 5, pp. 76-87.

3. Balkevich V.L. Tekhnicheskaya keramika M.: Stroyizdat, 1984, $256 \mathrm{p}$.

4. Gladun V.D., Akateva L.V., Kholkin A.I. Sinteticheskie silikaty kaltsiya. M.: Irisbuk, 2011, 232 p.

5. Gladun V.D., Andreeva N.N., Akateva L.V., Dragina O.Vol. Ekologiya i promyshlennost Rossii, 2000, no. 5, pp. 17-20.

6. Chakradhar R.P. S., Nagabhushana B.M., Chandrappa G.T., Ramesh K.P., Rao J.L. Materials Chemistry and Physics, 2006, Vol. 95, no. 1, pp. 169-175.

7. Hoa L.M.K., Lu M., Zhang Y. Adv. Colloid and Interface Sci., 2006, Vol. 121, pp. 9-23.

8. Koetz J, Kosmella S. Polyelectrolytes and Nanoparticles. New York: Springer, 2007.

9. Kokubo T., Kim H-M., Kawashita M. Biomaterials, 2003, Vol. 24, pp. 2161-2175.

10. Lin K., Chang J., Lu J. Materials Letters, 2006, Vol. 60, pp. 3007-3010

11. Li X., Shi J., Zhu Y., Shen W., Li H., Liang J., Gao J. Journal of Biomedical Materials Research Part B: Applied Biomaterials, 2007, Vol. 83B, no. 2, pp. 431-439.

12. Simitzis J., Baciu D. E. Digest Journal of Nanomaterials and Biostructures, 2012, Vol. 7, no. 4, pp. 1719-1725.

13. Simon S., Ciceo-Lucacel R., Radu T., Baia L. J. Mater. Sci.: Mater. Med., 2012, Vol. 23, pp. 1193-1201.

14. Lou X.W., Archer L.A., Yang Z. Advanced Materials, 2008, Vol. 20, pp. 3987-4019. 